\title{
Seasonal variations and the influence of COVID-19 pandemic on hemoglobin A1c, glycoalbumin, and low-density lipoprotein cholesterol
}

\author{
Kohzo Takebayashi $^{1}$ [D $\cdot$ Mototaka Yamauchi $^{1} \cdot$ Kenji Hara $^{1} \cdot$ Takafumi Tsuchiya $^{1} \cdot$ Koshi Hashimoto $^{1}$
}

Received: 6 December 2021 / Accepted: 20 February 2022 / Published online: 8 March 2022

(c) The Japan Diabetes Society 2022

\begin{abstract}
Aim The purpose of the study was to investigate seasonal variations in HbA1c, GA and LDL-C and to examine the effects of the COVID-19 pandemic on these variations and on glycemic and lipid control themselves in patients with type 2 diabetes. Patients and methods The subjects were outpatients with type 2 diabetes who had received standard treatment for glycemic control for more than 3 years. Data for patients who visited our hospital from January 2021 to March 2021 were retrospectively investigated based on electronic medical records.

Results $\mathrm{HbAlc}$ showed seasonal variation (high in winter-spring and low in summer-autumn), and this was similar during the COVID-19 pandemic. However, the mean HbA1c over 1 year was significantly elevated during the COVID-19 pandemic (7.53 $\pm 1.02 \%$ in 2020$)$ compared with the previous 2 years: $(7.34 \pm 0.91$ in $2018,7.39 \pm 0.93$ in $2019 ; 2020$ vs. $2018 ; 0.19 \%$, $P<0.001 ; 2020$ vs. $2019 ; 0.14 \%, P=0.0013)$ and the difference was larger in winter. GA showed no apparent seasonal variation, but mean GA during the COVID-19 pandemic was elevated compared with earlier years (2020 vs. 2018, $P<0.001$; 2020 vs. $2019, P<0.001)$. LDL-C did not show apparent seasonal variation and was unaffected by COVID-19 pandemic. Conclusion The COVID-19 pandemic influenced mean HbA1c and GA levels over 1 year, but did not affect seasonal variations, while LDL-C was not affected by COVID-19. Observation of these levels over a longer period is warranted to determine the longer-term influence of the COVID-19 pandemic.
\end{abstract}

Keywords Seasonal variation $\cdot \mathrm{HbA1c} \cdot \mathrm{GA} \cdot \mathrm{LDL}-\mathrm{C} \cdot \mathrm{COVID}-19$

\section{Introduction}

The main purpose of treatment of type 2 diabetes is to prevent progression of micro-angiopathies, such as neuropathy, retinopathy and nephropathy, and macro-angiopathies including peripheral arterial disease, ischemic heart disease and stroke. Intensive therapy for glycemic control is effective for prevention or delay of progression of these complications [1, 2]. Hemoglobin A1c (HbA1c) is a non-enzymatic glycation product of hemoglobin that reflects the average plasma glucose level in the previous 2-3 months [3] and is a marker for diagnosis and a target for treatment $[4,5]$.

Kohzo Takebayashi

takeb@silk.plala.or.jp

1 Department of Diabetes, Endocrinology and Hematology, Dokkyo Medical University Saitama Medical Center, Koshigaya, Saitama, Japan
However, the HbA1c value is also influenced by conditions, such as hemodialysis, age, genetic background, race/ethnicity, anemia and hemoglobinopathies [4]. HbA1c also shows seasonal variations in type 1 and type 2 diabetes, with higher levels in winter (cooler season) and nadir levels in summer (warmer season) [6-18], although different seasonal variations have also been suggested $[19,20]$. Therefore, treatment in which seasonal variations are taken into consideration may be desirable to achieve good glycemic control.

The reasons for seasonal variations in $\mathrm{HbA} 1 \mathrm{c}$ are unknown, but may involve differences in air temperature, the influence of seasonal changes in hormones such as vitamin $\mathrm{D}[21,22]$, and possible changes of physical activities and food intake. Among these factors, patients in regions with a large difference in temperature between summer and winter have more apparent seasonal variations of HbA1c [11]. In Japan, there are four distinct seasons in most regions. Koshigaya City, Saitama Prefecture, where our hospital is located, has a very hot and humid 
summer (one of the hottest in Japan) with a maximum temperature that can exceed $40^{\circ} \mathrm{C}$, while the winter is relatively cool and has a minimum temperature of about $0^{\circ} \mathrm{C}$, but with many sunny days [23]. Thus, Koshigaya City has four particularly distinct seasons, which makes the region suitable to explore seasonal variations of $\mathrm{HbA} 1 \mathrm{c}$ in patients with diabetes. Furthermore, the COVID-19 pandemic has changed lifestyles and caused considerable mental stress for many people since winter 2020 . Therefore, it is of interest to investigate the effects of the pandemic on seasonal variation of $\mathrm{HbA} 1 \mathrm{c}$ and glycemic control itself (i.e., mean HbA1c over 1 year).

Based on this background, in the current study, seasonal variations of $\mathrm{HbA} 1 \mathrm{c}$ were evaluated in patients with type 2 diabetes who visited our hospital as outpatients, including during the COVID-19 pandemic. We also simultaneously evaluated glyco-albumin (GA) as a marker of glycemic control that reflects mean plasma glucose levels over the previous 2-4 weeks [24], and low-density lipoprotein cholesterol (LDL-C) as a marker of circulating lipids, which may also show seasonal variation [25].

\section{Patients and methods}

Outpatients with type 2 diabetes who had received regular treatment for glycemic control from the same doctor (K.T.) for more than 3 years (visits from prior to March 2018) and visited the hospital from January 2021 to March 2021 were first identified from a retrospective evaluation of electronic medical records. Patients with repeated severe anemia due to chemotherapy for cancer or due to gastrointestinal bleeding caused by digestive system diseases were excluded before analyses based on the judgment of the physician in charge (K.T.). Patients with type 1 diabetes were also excluded to permit a focus on type 2 diabetes.

Data for HbA1c, GA and LDL-C from March 2018 to February 2021 were obtained from electronic medical records. The intervals between each visit were mostly 2-3 months (range 1-3 months). The four seasons of spring, summer, autumn and winter were defined as March-May, June-August, September-November, and December-February, respectively, and the years 2018, 2019 and 2020 were defined from March 2018-February 2019, March 2019-February 2020, and March 2020-February 2021. The 2020 year was also defined as the COVID-19 pandemic period because the serious effects of COVID-19 started in Japan in about March 2020 and have continued to the present time (i.e., April 2021) and most patients had not received the COVID-19 vaccine by the end of February 2021.

\section{Measurements of $\mathrm{HbA1c}$, GA, and LDL-C}

HbA1c was evaluated by an enzymatic assay using protease in the initial reaction and fructosyl-peptide oxidase (FPOX) and peroxidase (POD) in the second reaction (Nordia ${ }^{\circledR}$ N HbA1c, Sekisui Medical Inc., Tokyo, Japan). GA was measured using a Lucica GA-L kit (Asahi Kasei Pharma Co., Ltd, Tokyo, Japan). Serum LDL-C was measured by an enzymatic assay in a Cholestest LDL ${ }^{\circledR}$ kit (Daiichi Pure Chemicals Co., Ltd, Tokyo, Japan).

\section{Ethical considerations}

The Institutional Ethics Committee at Dokkyo Medical University Saitama Medical Center approved the study with a 6-month opt-out period (Approval no. 21014/ approval day: 4/26/2021).

\section{Statistical methods}

Differences of HbA1c, GA, and LDL-C among the four seasons in 2018, 2019 and 2020 (as defined above) and among the 3 years were evaluated using repeated measures analysis of variance (ANOVA) with a post hoc Holm test. Correlations between two variables were examined using Pearson's correlation analysis. All statistical analyses were performed using BellCurve for Excel software (Social Survey Research Information Co., Ltd, Tokyo, Japan). A $P$ value of less than 0.05 was estimated as indicating statistical significance (two-sided).

\section{Results}

\section{Clinical characteristics and laboratory data in the $\mathbf{2 9 0}$ registered patients at baseline (first visit after March 2018) are summarized in Table 1}

ThemeanvaluesforHbA1c $(n=290), \mathrm{GA}(n=267)$ andLDL-C $(n=280)$ per year (Fig. 1A-C) in 2018, 2019 and 2020 were $7.34 \pm 0.91,7.39 \pm 0.93,7.53 \pm 1.02 \% ; 18.64 \pm 3.88$, $19.25 \pm 3.98,19.87 \pm 4.35 \%$; and $111.98 \pm 28.63,110.80 \pm$ $29.38,110.52 \pm 28.38 \mathrm{mg} / \mathrm{dL}$, respectively. HbA1c was significantly higher in 2020 than in 2018 (change of $0.19 \%$, $P<0.001)$ and $2019(0.14 \%, P=0.0013)$. Similarly, GA was significantly higher in 2020 compared with 2018 and 2019 (both $P<0.001)$ and in 2019 compared to $2018(P<0.001)$. In contrast, LDL-C did not differ significantly among the 2018, 2019 and 2020 years.

The mean HbA1c, GA and LDL-C levels per month and for each season in 2018, 2019 and 2020 are shown in Figs. $2 \mathrm{~A}-\mathrm{C}$ and $3 \mathrm{~A}-\mathrm{C}$, respectively. The differences 
Table 1 Clinical features and laboratory data at baseline in patients with type 2 diabetes

\begin{tabular}{ll}
\hline No. (male/female) & $290(166 / 124)$ \\
Age (year) & $70.1 \pm 10.9$ \\
Duration of diabetes $(n)$ & \\
Year & \\
$0-4$ & 13 \\
$5-9$ & 74 \\
$10-14$ & 79 \\
$>15$ & 124 \\
BMI (kg/m $\left.{ }^{2}\right)$ & $24.7 \pm 4.4$ \\
HbA1c $(\%)$ & $7.4 \pm 1.1$ \\
GA (\%) & $19.2 \pm 4.4$ \\
LDL-C (mg/dL) & $111.3 \pm 30.1$ \\
eGFR (ml/min/1.73 m $\left.^{2}\right)$ & $63.6 \pm 18.1$ \\
Diabetic therapy $(n)$ & \\
Sulfonylureas and glinides & 132 \\
Metformin & 111 \\
Pioglitazone & 18 \\
$\alpha G I$ & 76 \\
DPP4-I & 150 \\
SGLT2-I & 18 \\
GLP-1RA & 21 \\
Insulin & 69 \\
Statins $(n)$ & 76 \\
\hline
\end{tabular}

Data are expressed mean \pm standard deviation

Baseline: first visit after March 2018

$n$ : number of the patients

$B M I$ body mass index, $H b A l c$ hemoglobin A1c, $G A$ glycoalbumin, $L D L-C$ low-density lipoprotein cholesterol, $e G F R$ estimated glomerular filtration rate

Diabetic therapy: $\alpha G I \alpha$ glucosidase inhibitors, DPP4-I dipeptidyl peptidase 4 inhibitors, SGLT2-I Sodium Glucose cotransporter 2 inhibitors, GLP-1RA glucagon-like peptide (GLP)-1 receptor agonists. In therapies, most patients were receiving combination therapy for diabetes between the maximum and minimum monthly mean $\mathrm{HbA} 1 \mathrm{c}$ were $0.33 \%, 0.37 \%$ and $0.7 \%$ in 2018,2019 and 2020, respectively. Comparisons of these variables among four seasons were performed in each year. In 2018 and 2019, HbA1c was significantly higher in spring and winter than in summer and autumn, while in 2020, HbA1c was significantly higher in winter compared to spring, summer and autumn (all $P<0.001$ ). Thus, in the non-COVID-19 period, $\mathrm{HbA} 1 \mathrm{c}$ was higher in the winter-spring season and lower in the summer-autumn season, but in the COVID19 period, the winter $\mathrm{HbA} 1 \mathrm{c}$ was higher than all other seasons. In the winter seasons in 2018, 2019, and 2020, $\mathrm{HbA1c}$ was $7.47 \pm 1.11,7.52 \pm 1.08$, and $7.7 \pm 1.24 \%$, respectively; and the winter $\mathrm{HbA1c}$ in 2020 was significantly higher than the values in 2018 (change $0.23 \%$, $P<0.001)$ and 2019 (0.18\%, $P=0.0048)$.

GA was significantly higher in winter compared to spring in $2018(P=0.0029)$ and significantly higher in spring compared to autumn in $2019(P=0.0389)$, indicating no clear seasonal variation in GA. LDL-C was significantly higher in winter compared to spring $(P=0.0186)$ and summer $(P<0.001)$ in 2018 and significantly higher in spring compared to summer in $2020(P=0.0113)$.

In sub-analyses for HbA1c, patients $(n=129)$ with no change in dose or type of anti-diabetes drugs over the 3-year study period showed similar seasonal patterns to those for all patients, although comparison of the spring value with those in summer and autumn in 2018 did not reach statistical significance (Fig. 4A). Patients $(n=69)$ receiving insulin therapy with or without other anti-diabetes drugs also had similar seasonal patterns of $\mathrm{HbA} 1 \mathrm{c}$ compared to those for all patients, although again a significant difference was not obtained in 2018 (Fig. 4B).

HbAlc showed significant positive correlations with GA $(r=0.5961, P<0.001)$ and LDL-C $(r=0.1140, P=0.0175)$ at baseline (first visit after March 2018). Correlations of monthly HbA1c, GA, and LDL-C with temperature or hours of sunlight in Koshigaya City were examined based on data from the website of the Japan Meteorological Agency (26). $\mathrm{HbA1 \textrm {c }}$ was significantly negatively correlated with temperature in $2018(r=-0.6048, P=0.0372), 2019(r=-0.7615$,

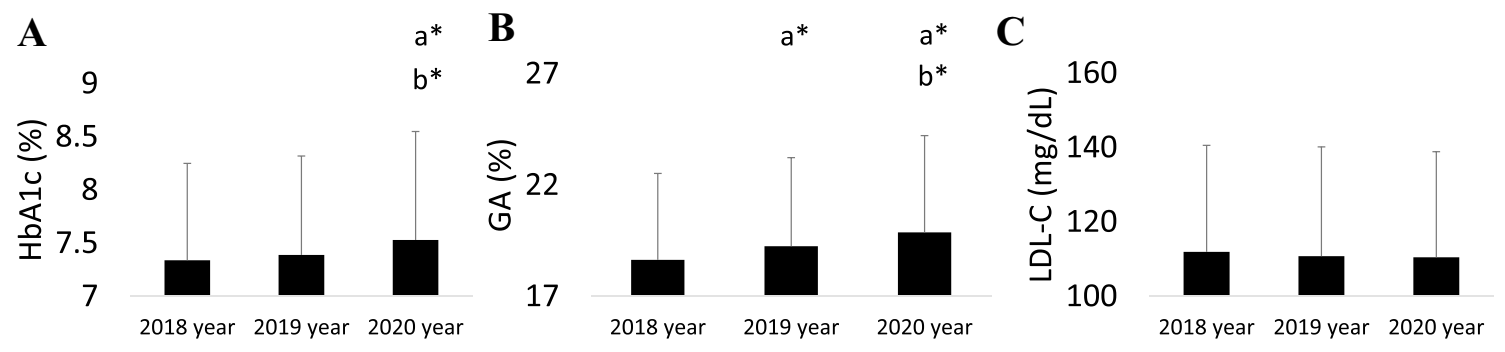

Fig. 1 Comparisons of mean hemoglobin A1c (HbA1c) (A), glycoalbumin (GA) (B), and low-density lipoprotein cholesterol (LDL-C) (C) in 2018, 2019 and 2020. a vs. 2018 , b vs. $2019, * P<0.001$ 
Fig. 2 Variations per month over 3 years for hemoglobin A1c (HbA1c) (A), glycoalbumin (GA) (B), and low-density lipoprotein cholesterol (LDL-C) (C)

Fig. 3 Seasonal variation over 3 years for hemoglobin A1c (HbA1c) (A), glycoalbumin (GA) (B), and lowdensity lipoprotein cholesterol (LDL-C) (C). a vs. spring, b vs. summer, c vs. autumn, $* P<0.001,+P<0.05$
7

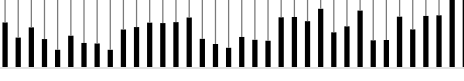

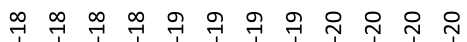

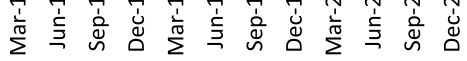

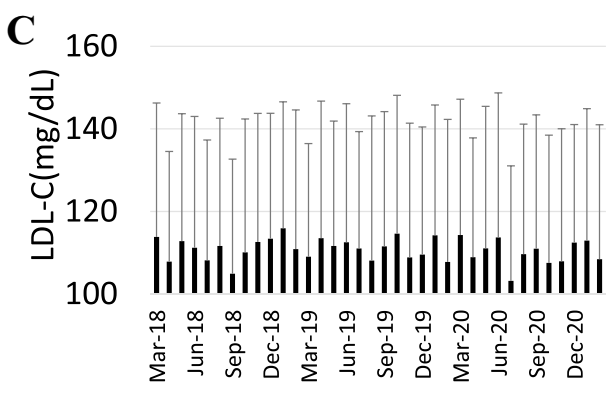

\section{A 10

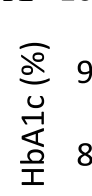

B 32

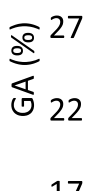

17

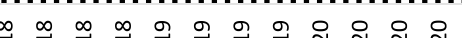

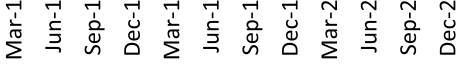
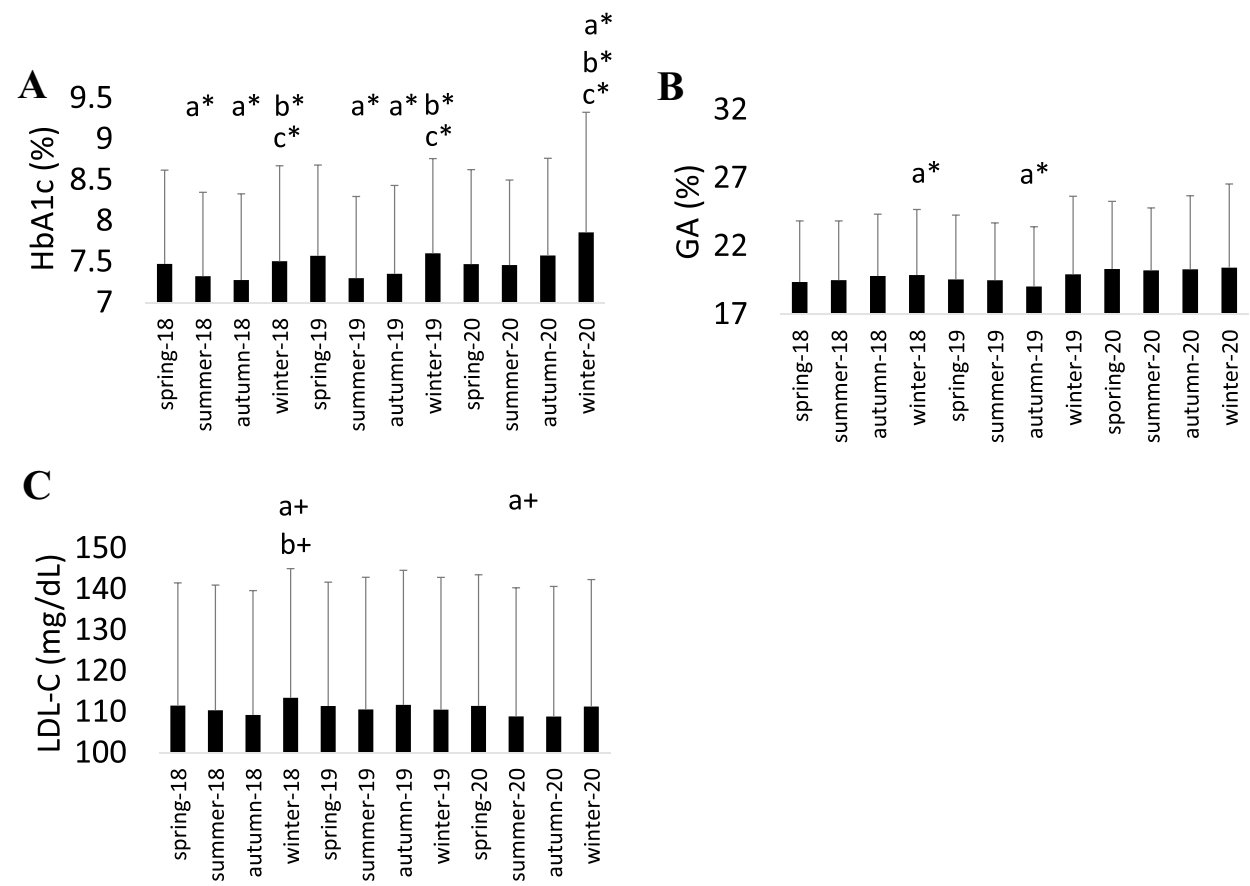

$P=0.0040)$, and $2020(r=-0.7043, P=0.0106)$. In contrast, GA and temperature showed no correlation in any year, and LDL-C was significantly negatively correlated with temperature only in $2018(r=-0.5944, P=0.0415)$. There were no correlations of $\mathrm{HbA} 1 \mathrm{c}, \mathrm{GA}$, or LDL-C with hours of sunlight in each year. There were also no differences in the mean yearly temperatures (calculated as the mean of monthly temperatures) in comparisons of 2018, 2019 and 2020 (all $P=1.0$ ).

\section{Discussion}

The results of the study showed differences in maximum and minimum monthly HbA1c in 2018 and 2019 of $0.33 \%$ and $0.37 \%$, respectively. These findings are similar to those in previous studies showing differences of about $0.2-0.5 \%$ $[6-8,15,16,20]$. HbAlc was higher in winter-spring and reached a nadir in summer-autumn in both years, which is also consistent with previous studies showing a higher $\mathrm{HbA} 1 \mathrm{c}$ in cooler seasons and a nadir in hotter seasons 
Fig. 4 Seasonal variation over 3 years for hemoglobin A1c (HbA1c) in patients with no change in dose or type of antidiabetes drugs over the 3-year period (A) and in patients who received insulin therapy with or without other anti-diabetes drugs (B). a vs. spring, b vs. summer, c vs. autumn, $* P<0.001,+P<0.05$

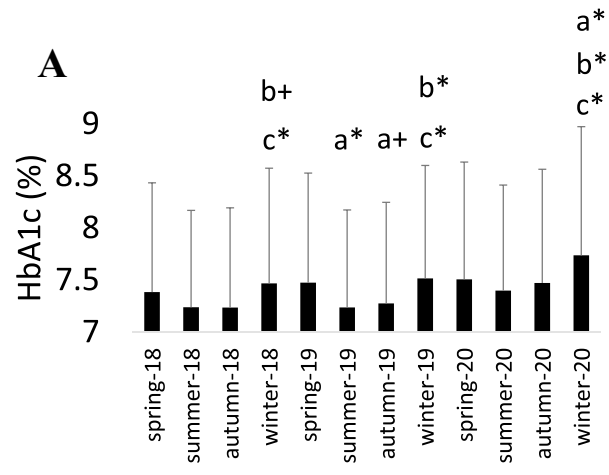

No Drug Change

a*

$b^{*}$
B

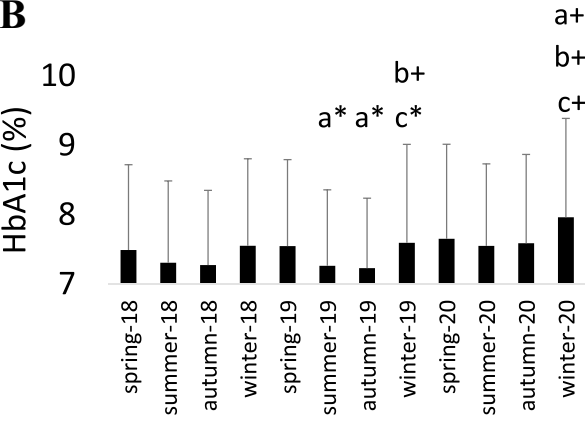

Insulin therapy
[6-17]. The relatively high HbA1c in spring and the relatively low value in autumn are due to a time lag because $\mathrm{HbA} 1 \mathrm{c}$ reflects glycemic control for the previous 2-3 months [3]. Sakamoto et al. found similar results for $\mathrm{HbA} 1 \mathrm{c}$ of a lower value in summer-autumn and a higher value in winter-spring [12]. The difference in maximum and minimum monthly HbA1c in 2020 (the COVID-19 period) of $0.7 \%$ was larger, during a period in which there may have been changes in lifestyles. Higher values in winter-spring were maintained in 2020, although the mean HbA1c in spring 2020 was relatively low. This may also be due to a time lag since the effects of the COVID-19 pandemic on HbA1c may only have started in about May 2020 in Japan. The results for all 3 years were similar for all patients, for patients without a change in diabetes treatment during the study period, and even for patients treated with insulin, in whom variation of glycemic control is likely to be larger because of a possible decrease in endogenous insulin secretion capacity. Therefore, the observation of seasonal variation of $\mathrm{HbAlc}$ in the entire cohort is not biased by changes of drugs and appears to be robust.

The reasons for seasonal variations of $\mathrm{HbA} 1 \mathrm{c}$ are still not fully apparent. However, temperature, changes of physical activity or food intake, and hormonal variation such as vitamin $\mathrm{D}$, which can affect circulating glucose levels and insulin resistance [21,22], may be associated with seasonal variation. A significant negative correlation between monthly mean $\mathrm{HbA} 1 \mathrm{c}$ and monthly mean temperature has been shown $[8,10]$, and we found a similar strong negative correlation between these variables, suggesting that a relatively low temperature is associated with worsened $\mathrm{HbA} 1 \mathrm{c}$. Interestingly, despite the seasonal variation persisting in 2020 during the COVID-19 pandemic, the mean HbA1c was significantly larger than those in 2018 and 2019 (differences of $0.19 \%$ and $0.14 \%$, respectively) and was particularly larger in winter $(0.23 \%$ and $0.18 \%$, respectively). In contrast, the mean temperatures in 2018, 2019 and 2020 did not differ significantly. Therefore, the worsened glycemic control assessed by HbA1c in 2020 appears to be due to reasons other than temperature. The effects of COVID-19 pandemic included self-imposed limitations on going out and promotion of telework at home, which may have resulted in lack of exercise and increased food intake, including a probable increase of snacks. Thus, particularly careful attention to glycemic control is needed if the COVID-19 period continues into the winter of 2021.

Seasonal variations of GA were also evaluated as another marker of glycemic control. However, we found no apparent seasonal variation of GA in all 3 years and no correlation between monthly mean GA and monthly mean temperature in each year, as also found in the only previous study of this effect [10]. The reasons for these negative findings are unclear. GA reflects shorter-term glycemic control compared with $\mathrm{HbA1c}$ [24] and is negatively influenced by body fat mass and visceral adipose tissues, unlike HbA1c [27]. However, it is unclear whether these differences influence the results for seasonal variation. The mean GA level was significantly elevated in the COVID-19 period (2020) compared with those in 2018 and in 2019, similarly to HbA1c. This suggests that GA may have a different clinical utility compared with that of $\mathrm{HbA1c}$ as a marker of glycemic control, since GA is not affected by seasonal variation.

Seasonal variation of LDL-C levels was also investigated. LDL-C has previously been shown to have seasonal variation, with higher levels in cooler seasons and lower levels in warmer seasons [25]. LDL-C levels in our patients were slightly lower in summer-autumn and slightly higher in winter-spring in 2018 and 2020, but did not differ between seasons in 2019. There was a weak but significant correlation between monthly mean LDL-C and monthly mean temperature only in 2018. Based on these findings, we concluded that there was no apparent seasonal variation on LDL-C. Interestingly, the mean yearly LDL-C levels were quite similar in 2018, 2019, and 2020, which suggests that LDL-C was not influenced by the COVID-19 pandemic. The different results for $\mathrm{HbA1c}$ and LDL-C are difficult to explain, but speculatively, the possible increase of food intake (snacks) at home in the COVID-19 periods may have increased intake 
of carbohydrates rather than lipids although the results may be different in Europe and the US, where eating habits and types of snacking are different compared with those in Japan. In addition, lack of exercise would generally influence $\mathrm{HbA} 1 \mathrm{c}$ rather than LDL-C. However, a more detailed investigation is needed to explain these results more fully.

In the current study, seasonal variations of $\mathrm{HbAlc}$ and GA as markers of glycemic control, and LDL-C as a lipid marker were evaluated over a 3 -year period. The limitations of the study include this relatively short period and the small number of patients. Furthermore, we could not accurately evaluate the change of body weight due to the nature of the retrospective observational study; the descriptions of body weight were mainly based on the patients' self-report and there were partially missing descriptions on electronic medical records. This is important limitation in this study. However, the study period also included 1 year of the COVID-19 pandemic, in which lifestyles changed compared to those under normal conditions. Other advantages of the study were its performance in patients examined by a single doctor at one center, which eliminates bias from different treatment policies, and the standard measurements used for $\mathrm{HbA} 1 \mathrm{c}$, GA and LDL-C.

In conclusion, $\mathrm{HbA} 1 \mathrm{c}$ showed seasonal variation, with a high level in winter-spring and a low level in summer-autumn, and this variation was similar in the nonCOVID-19 and COVID-19 periods. However, mean yearly HbA1c was significantly elevated during the COVID-19 period compared with the previous 2 years, and the difference was larger in winter. In contrast, GA did not show apparent seasonal variation, but mean GA during the COVID-19 period was significantly elevated compared with the non-COVID-19 years. LDL-C did not show an apparent seasonal variation, and was not influenced by COVID-19 pandemic. The observed effects of the COVID19 pandemic on HbA1C and GA warrant further longerterm studies of these variables.

Acknowledgements This work was supported in part by Grants-inAid for Scientific Research (KAKENHI) from the Japan Society for the Promotion of Science (JSPS) [Grant numbers 19K09018 (Koshi Hashimoto.) and 20K11394 (Kenji Hara)].

\section{Declarations}

Conflict of interest All authors have no conflict of interest to declare.

Research involving human participants or animals The study with human subjects

Informed consent The information of this retrospective study was posted during 6-month opt-out period. Name of institutional committee: the institutional ethics committee at Dokkyo Medical University Saitama Medical Center: Approval no. 21014/ approval day: 4/26/2021.

\section{References}

1. UK Prospective Diabetes Study (UKPDS) Group. Intensive blood-glucose control with sulphonylureas or insulin compared with conventional treatment and risk of complications in patients with type 2 diabetes (UKPDS 33). Lancet. 1998;352:837-53 (Erratum, Lancet 1999;354: 602)

2. Holman RR, Paul SK, Bethel MA, Matthews DR, Neil HA. 10 -year follow-up of intensive glucose control in type 2 diabetes. N Engl J Med. 2008;359:1577-89.

3. Sacks DB, Arnold M, Bakris GL, Bruns DE, Horvath AR, Kirkman MS, Lernmark A, Metzger BE, Nathan DM, National Academy of Clinical Biochemistry. Evidence-Based Laboratory Medicine Committee of the American Association for clinical chemistry guidelines and recommendations for laboratory analysis in the diagnosis and management of diabetes mellitus. Diabetes Care. 2011;6:e61-99.

4. American Diabetes Association. Classification and diagnosis of diabetes: standards of medical care in diabetes-2021. Diabetes Care. 2021;44(Supplement 1):S15-33.

5. American Diabetes Association. Glycemic targets: standards of medical care in diabetes-2021. Diabetes Care. 2021;44(Supplement 1):S73-84.

6. Tseng CL, Brimacombe M, Xie M, Rajan M, Wang H, Kolassa J, Crystal S, Chen TC, Pogach L, Safford M. Seasonal patterns in monthly hemoglobin A1c values. Am J Epidemiol. 2005;161:565-74.

7. Sakura H, Tanaka Y, Iwamoto Y. Seasonal fluctuations of glycated hemoglobin levels in Japanese diabetic patients. Diabetes Res Clin Pract. 2010;88:65-70.

8. Kim YJ, Park S, Yi W, Yu KS, Kim TH, Oh TJ, Choi J, Cho YM. Seasonal variation in hemoglobin a1c in Korean patients with type 2 diabetes mellitus. J Korean Med Sci. 2014;29:550-5.

9. Maguire GA, Edwards OM. Seasonal variation in glycated haemoglobin in diabetics. Ann Clin Biochem. 2001;38(Pt 1):59-60.

10. Tanaka K, Meguro S, Tanaka M, Irie J, Saisho Y, Itoh H. Difference of seasonal variation between glycated albumin and glycated haemoglobin. Ann Clin Biochem. 2018;55:583-7.

11. Higgins T, Saw S, Sikaris K, Wiley CL, Cembrowski GC, Lyon AW, Khajuria A, Tran D. Seasonal variation in hemoglobin A1c: is it the same in both hemispheres? J Diabetes Sci Technol. 2009;3:668-71.

12. Sakamoto M, Matsutani D, Minato S, Tsujimoto Y, Kayama Y, Takeda N, Ichikawa S, Horiuchi R, Utsunomiya K, Nishikawa $\mathrm{M}$. Seasonal variations in the achievement of guideline targets for $\mathrm{HbA}_{1 \mathrm{c}}$, blood pressure, and cholesterol among patients with type 2 diabetes: a nationwide population-based study (ABC study: JDDM49). Diabetes Care. 2019;42:816-23.

13. Sohmiya M, Kanazawa I, Kato Y. Seasonal changes in body composition and blood $\mathrm{HbA} 1 \mathrm{c}$ levels without weight change in male patients with type 2 diabetes treated with insulin. Diabetes Care. 2004;27:1238-9.

14. Xue L, Liang H, Jiang X. Circannual temperature-related variation in hemoglobin A1c is unlikely to affect its use as a diagnostic test for type 2 diabetes. Clin Lab. 2012;58:481-8.

15. Gikas A, Sotiropoulos A, Pastromas V, Papazafiropoulou A, Apostolou O, Pappas S. Seasonal variation in fasting glucose and $\mathrm{HbA} 1 \mathrm{c}$ in patients with type 2 diabetes. Prim Care Diabetes. 2009;3:111-4.

16. Ishii H, Suzuki H, Baba T, Nakamura K, Watanabe T. Seasonal variation of glycemic control in type 2 diabetic patients. Diabetes Care. 2001;24:1503.

17. Asplund J. Seasonal variation of $\mathrm{HbA} 1 \mathrm{c}$ in adult diabetic patients. Diabetes Care. 1997;20:234. 
18. Pereira MT, Lira D, Bacelar C, Oliveira JC, de Carvalho AC. Seasonal variation of haemoglobin A1c in a Portuguese adult population. Arch Endocrinol Metab. 2015;59:231-5.

19. Carney TA, Guy SP, Helliwell CD. Seasonal variation in $\mathrm{HbA} 1 \mathrm{c}$ in patients with type 2 diabetes mellitus. Diabet Med. 2000;17:554-5.

20. Raphael A, Friger M, Biderman A. Seasonal variations in HbA1c among type 2 diabetes patients on a semi-arid climate between the years 2005-2015. Prim Care Diabetes. 2021;15:502-6.

21. Cantorna MT. Vitamin D and autoimmunity: is vitamin D status an environmental factor affecting autoimmune disease prevalence? Proc Soc Exp Biol Med. 2000;223:230-3.

22. Baynes KC, Boucher BJ, Feskens EJ, Kromhout D. Vitamin D, glucose tolerance and insulinaemia in elderly men. Diabetologia. 1997;40:344-7.

23. Japan Meteorological Agency Home Page (in Japanese). http:// www.data.jma.go.jp/obd/stats/etrn/view/rank_a.php?prec_ no $=43 \&$ block_no $=0364 \&$ year $=\&$ month $=\&$ day $=\&$ view $=a 2$. Accessed 1 May 2021

24. Zendjabil M. Glycated albumin. Clin Chim Acta. 2020;502:240-4.

25. Ma X, Yan H, Zhang H, Wang M, Zhang Q, Zhou X. Progress in the seasonal variations of blood lipids: a mini-review. Lipids Health Dis. 2020;19:108.

26. Japan Meteorological Agency Home page (in Japanese). http:// www.jma.go.jp/jma/index.html. Accessed 1 May 2021.

27. Furusyo N, Hayashi J. Glycated albumin and diabetes mellitus. Biochim Biophys Acta. 2013;1830:5509-14.

Publisher's Note Springer Nature remains neutral with regard to jurisdictional claims in published maps and institutional affiliations. 